Original article

\title{
Regional pattern of child undernutrition, calorie consumption, non-food expenditure and wealth in India
}

\author{
Junaid Khan ${ }^{\text {a," }}$, Sanjay K. Mohanty ${ }^{\mathrm{b}}$ \\ ${ }^{a}$ International Institute for Population Sciences, Govandi Station Road, Deonar, Mumbai, 400088, India \\ ${ }^{\mathrm{b}}$ Professor, Department of Fertility Studies, International Institute for Population Sciences, Govandi Station Road, Mumbai, 400088, Maharashtra, India
}

\section{A B S T R A C T}

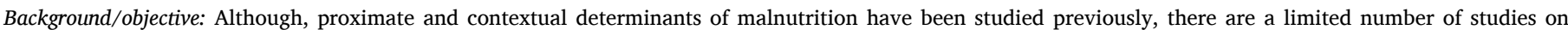

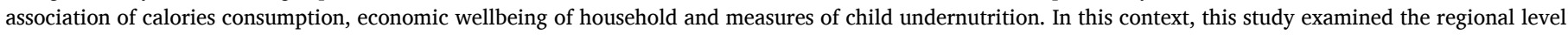
variation in child undernutrition in terms of calories consumption, monthly per capita non-food expenditure (MPCNFE) and mean wealth score.

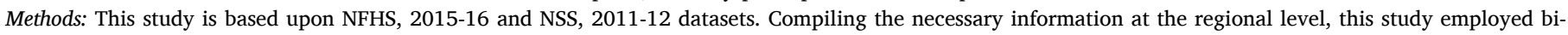
variate cross-tabulation, correlation analysis and multivariate OLS regression analysis.

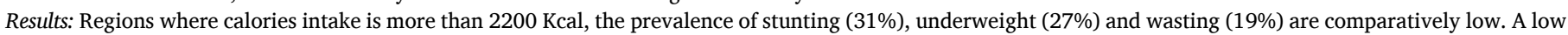

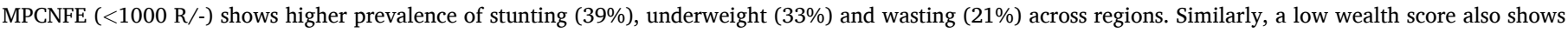

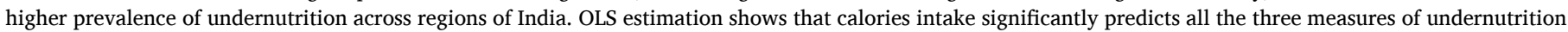

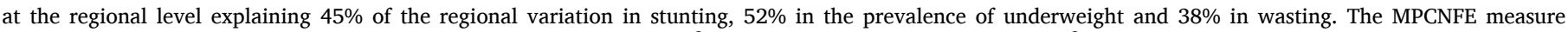

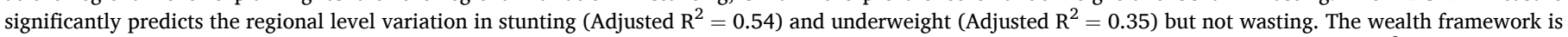
observed to be weak and shows statistically significant association with stunting only and the explained variation is also found low (Adjusted $\mathrm{R}^{2}=0.16$ ).

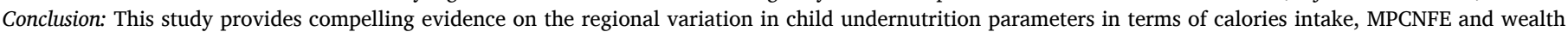
score.

\section{Introduction}

India has achieved considerable economic growth during the last decade; yet, malnourishment among Indian children has not shown significant improvement despite several nutrition specific and nutrition sensitive interventions and multisectoral approaches. State level prevalence of child undernutrition is still quite high in terms of stunting, underweight and wasting and states in the Central part (Chhattisgarh, Madhya Pradesh and Uttar Pradesh) of India and Bihar and Jharkhand from Eastern part of India are the states where more than two-fifth of the children are still stunted and a similar proportion are underweight. ${ }^{1}$ This is despite the fact that the standard of living of Indian household has improved over time. It is also estimated that the share of food expenditure in total expenditure declined from $73 \%$ to $55 \%$ in rural areas and $64 \%-42 \%$ in urban areas during 1972-73 and 2004-05 with a sharper decline in urban areas. ${ }^{2,3}$ Per capita calories intake also declined in both the rural and urban areas across India during 1983 and 2011-12. ${ }^{2,3}$

In India, it is observed that the prevalence of stunting, underweight and wasting among children aged less than five years show a decreasing pattern across the richer wealth quintiles. ${ }^{1}$ As per the estimates from the different rounds of National Family Health Survey (NFHS); it has been estimated that more than half of the children less than five years of age from the lowest wealth quintile are still stunted and underweight as well. ${ }^{1,4,5}$ Sixty percent of children less than five years of age during 2005-06 from the lowest wealth quintile were stunted whereas $57 \%$ were underweight and $25 \%$ were wasted. ${ }^{5}$ Notably, the prevalence of stunting and underweight in the poorest economic (wealth) class reduced by approximately $14 \%$ between $2005-06$ and 2015-16 whereas it declined by only three percent for wasting. ${ }^{1,5}$ It is also observed that the prevalence of wasting among children from the middle, rich and richest wealth quintile increased by $7 \%, 16 \%$ and $40 \%$ respectively between 2005-06 and 2015-16. , $^{1,5}$

The different rounds of the NFHS surveys provide estimates of nutritional outcome using height and weight of the under-five children and relate the anthropometric measures of child undernutrition with wealth index to understand the economic gradient of undernutrition. However, the estimates of calories intake are not available in the NFHS data. In this regard, the different consumption-expenditure rounds of the National Sample Survey (NSS) serve an important purpose in collecting a detailed information on food consumption and non-food expenditure

\footnotetext{
* Corresponding author. International Institute for Population Sciences, Govandi Station Road, Mumbai, 400088, Maharashtra, India.

E-mail addresses: junstatiips@gmail.com (J. Khan), sanjayiips@yahoo.co.in (S.K. Mohanty).
} 
across households in India. From NSS data, estimates of monthly per capita non-food expenditure (MPCNFE), and computed per capita calories intake are used in this study. The household level estimate of MPCNFE is one of the efficient measures of economic wellbeing of the household at the micro level while the aggregated estimate of MPCE is also a prospective and parallel measure which is computed with an underlying economic motivation to identify the economic status at the macro level.

There has been an increase in consumption expenditure, income and wealth distribution across states and socio-economic groups but no significant reduction in malnutrition level has been observed in India. ${ }^{6}$, ${ }^{11}$ Specifically, there has been a decline in poverty level (both consumption and asset poverty). However, this decline is not consistent with decline in undernutrition. Rich states like Maharashtra and Gujarat with higher per capita income have shown higher rates of undernutrition; on the other hand, states like Bihar, Odisha with lower per capita income have also shown higher level of undernutrition. ${ }^{1,5,6}$

Household's economic wellbeing can be measured by consumption or wealth depending upon the availability of the data across the surveys. The poverty measure derived from consumption referred as monetary poverty which is the official poverty estimate used in India. According to Tendulkar estimates $2011-12$, about $13.7 \%$ of the urban population lived below poverty line while $25.7 \%$ in rural areas lived below poverty line with large variations across states. ${ }^{6}$ On the other hand, the NFHS data is exclusively used by the researchers to define wealth poverty considering the wealth distribution across the households. Some researchers use the poorest and the poor quintile of the wealth index to define wealth poverty while others use a percentile cut-off based on consumption poverty. ${ }^{7-9}$ In this study, a regional analysis has been framed to examine the association of calories intake, MPCNFE and wealth with the measures of undernutrition. The analyses have been conceptualized primarily for two reasons. First, regions of India are classified based on agro climatic conditions and the regions show larger variations in the level of socio-economic development and nutritional outcomes. Second, though there has been a decline in money metric poverty across states and regions of India, the prevalence of undernutrition remained high. Moreover, the NSS sample size is adequate to design a regional level analysis and not adequate at district level. So, the question arises whether the measures of undernutrition vary by the different economic measures such as MPCNFE and wealth index across the regions of India. Particularly, how does consumption and wealth poverty are spatially related with undernutrition across the NSS defined regions of India? So, the aim of this study is to examine the regional pattern of undernutrition and its association with calorie consumption, MPCNFE and wealth poverty. The study hypothesized that the association between measures of undernutrition with calorie consumption, MPCNFE and wealth score is similar across NSS regions of India. Thus this study explores the regional level variation in the prevalence of stunting, underweight and wasting in terms of calories intake, MPCNFE and wealth.

\section{Data \& methods}

We utilized the unit level data from the consumption expenditure survey round (1.0), Type 2 schedule of 68th National Sample Survey (NSS) conducted during July 2011 and June 2012. NSS adopts a stratified, multistage cluster sampling design to collect the sample for all the states and union territories. A total of 364 questions were asked during 68th round of the survey to collect the specific data on household's consumption expenditure over two reference periods- 30 days and 365 days. Of the total questions on consumption expenditure, the data provides pertinent information on 142 food items consumed during the reference period. The instrument, sampling methods and the detailed report are available publicly. ${ }^{6}$ All the NSS rounds are hierarchical in nature and beyond states, region being the second disaggregated level after states, regional level estimates are reproducible. A total of 101, 651 households from 35 states and union territories were surveyed across 88 NSS regions of India in the 68th round of the survey. The National Sample Survey Organization (NSSO) conducts the consumer expenditure survey quinquennially with the prime objective to provide the estimates of household's economic wellbeing. A detailed schedule on food and non-food expenditure was collected in a reference of 7 days, 30 days and 365 days. These information are compiled for the analysis and the monthly per capita non-food expenditure (MPCNFE) is computed which is used as the key indicator of economic wellbeing of the household in this study. The survey also records the specific quantities of various items of consumption of each food items being consumed by the household during the reference period. The last four NSS reports on nutritional intake in India are those based on NSS's 50th round (1993-94), 55th round (1999-2000), 61st round (2004-05) and 66th round (2009-10) of the consumer expenditure surveys. The present study is based on the 68th round of the surveys conducted during 2011-12. From NSS 68th round, we compiled the necessary information on calorie consumption, monthly non-food expenditure, wealth score and other demographic information. On the other hand, the region level estimates of child undernutrition are computed using the recent round of National Family Health Survey, 2015-16.

NSS data used in this study for analysis is publicly available and unit level data could be obtained upon a data request through the Social Science Data Repository of the Indian Council of Social Science Research (ICSSR), subject to non-profit and academic interest only. NFHS-4 data used in this study is also publicly available and unit level data could be accessed upon a data request through the Demographic and Health Surveys (DHS).

\subsection{Outcome variables}

Child undernutrition: The main outcome variables of this study are the age-sex standardized anthropometric measures of child undernutrition, namely-stunting, underweight and wasting. The undernutrition prevalence is measured at regional level using the recent round of $\mathrm{Na}$ tional Family Health Survey, 2015-16.

\subsection{Key independent variables}

Per day per capita calories intake: In this study, we calculated household level per day per capita calories intake using household's total consumption of food. To compute total energy consumed, we used the nutrition chart by Indian Council of Medical Research. ${ }^{10}$ Using the nutrition chart, food item specific calories were compiled to compute the total energy consumed for each of the items and thus at the household level we converted the total quantity of food consumed into equivalent energy. Per capita calories intake is the household size adjusted measure of the calories intake.

Monthly per capita non-food expenditure (MPCNFE): Household's consumer expenditure is the total expenditure incurred on domestic consumption during the reference period which is the sum of all the monetary expenditures incurred for the consumption of various groups of items, namely (i) food, (ii) fuel \& light, entertainment etc. (iii) clothing and footwear and (iv) miscellaneous goods and services and durable articles. So, the monthly non-food expenditure is household's total consumption expenditure excluding the expenditure on food items. The total monthly non-food expenditure is adjusted for household size and every member from the same household is intuitively assigned the same monthly per capita non-food expenditure (MPCNFE).

Wealth Index: As per the survey instrumentation, NSS considers those goods which have a lifetime of one year or more with an exception to petty durable goods such as spectacles, torches, locks, umbrellas, etc., are excluded. As per the NSS guidelines, consumption expenditure on durable goods includes both expenditure on purchase and the corresponding expenditure incurred to repair and for the construction of household durables. On the other hand, for land and residential 
building, only expenditure on repair and construction is included. Durable goods include furniture and fixtures, "entertainment" durables such as radios, TV, VCR/VCP/DVD players, tape recorders and CD players, cameras, musical instruments, jewelry and ornaments, crockery and utensils, cooking and other household appliances such as fans, air conditioners, air coolers, etc. Using the household-based information on consumer durables, sector-wise integrated wealth score is generated using principal component analysis.

For this study, region level estimates of per capita calorie consumption, MPCNFE and median/mean wealth score are generated from NSS, 2011-12 round of data. Socio-economic and demographic confounders are also compiled from NSS, 2011-12. The measures of undernutrition are compiled from NFHS, 2015-16 rounds. Region level maps are generated using GeoDa. Two-way scatterplots are drawn, pairwise correlations are estimated and OLS estimation is performed to check the empirical association. All the statistical analyses are performed using STATA version 14.1.

\subsection{Statistical analyses}

A bivariate analysis is done to estimate the mean prevalence of stunting, underweight and wasting using the data information compiled at the region (NSS regions of India) level. Pair-wise correlation is estimated between the three different parameters of undernutrition and calories intake, MPCNFE and wealth score. Finally, OLS regression is performed to examine the unadjusted and adjusted effects of calories intake, MPCNFE and wealth score on different undernutrition parameters.

\section{Results}

\subsection{Regional pattern of calories intake, MPCNFE and wealth score}

Fig. 1 shows the regional pattern of calories intake (per day per capita) across India. There are around 11 regions where per day per capita calorie consumption is less than $1900 \mathrm{Kcal}$ and the regions are clustered mainly in the North Eastern part of India (regions from the states of Arunachal Pradesh, Nagaland and Meghalaya), along the Konkan coast (Coastal Maharashtra), part of Malabar Coast (Northern Kerala), Inland Northern Karnataka and in Tamil Nadu. While, there are only 15 regions found where per day per capita calories intake is more than $2200 \mathrm{Kcal}$. These regions are distributed over the Northern part of India across Trans Himalayan \& Southern region, Uttarakhand, Central Himachal Pradesh, Jammu \& Kashmir and its Mountainous range, Southern Punjab, North-Western and South-Eastern Rajasthan. Kachchh Gujarat from the Western India and Inland North-Eastern Telangana from South India also fall in this category of comparatively higher calorie consumption.

Fig. 2 shows the regional pattern of monthly per capita non-food expenditure (MPCNFE). It is observed that 25 regions show less than 500 Rs/- monthly per capita non-food expenditure, 43 regions show moderate MPCNFE between 500 and 1000 Rs/- and rest of the 19 regions show highest MPCNFE which is greater than 1000 Rs/-. Regions like Plains Eastern Assam, Cachar Plains Assam, Central Assam, and Tripura from North-East India; Northern Bihar, Central Bihar, Jharkhand, Northern Odisha, Southern Odisha, Coastal Odisha, Western and Eastern plains of West Bengal, Himalayan Bengal from East India; Central Uttar Pradesh, Southern Uttar Pradesh, Eastern Uttar Pradesh, Southern Chhattisgarh, Mahanadi Basin from Central India constitute

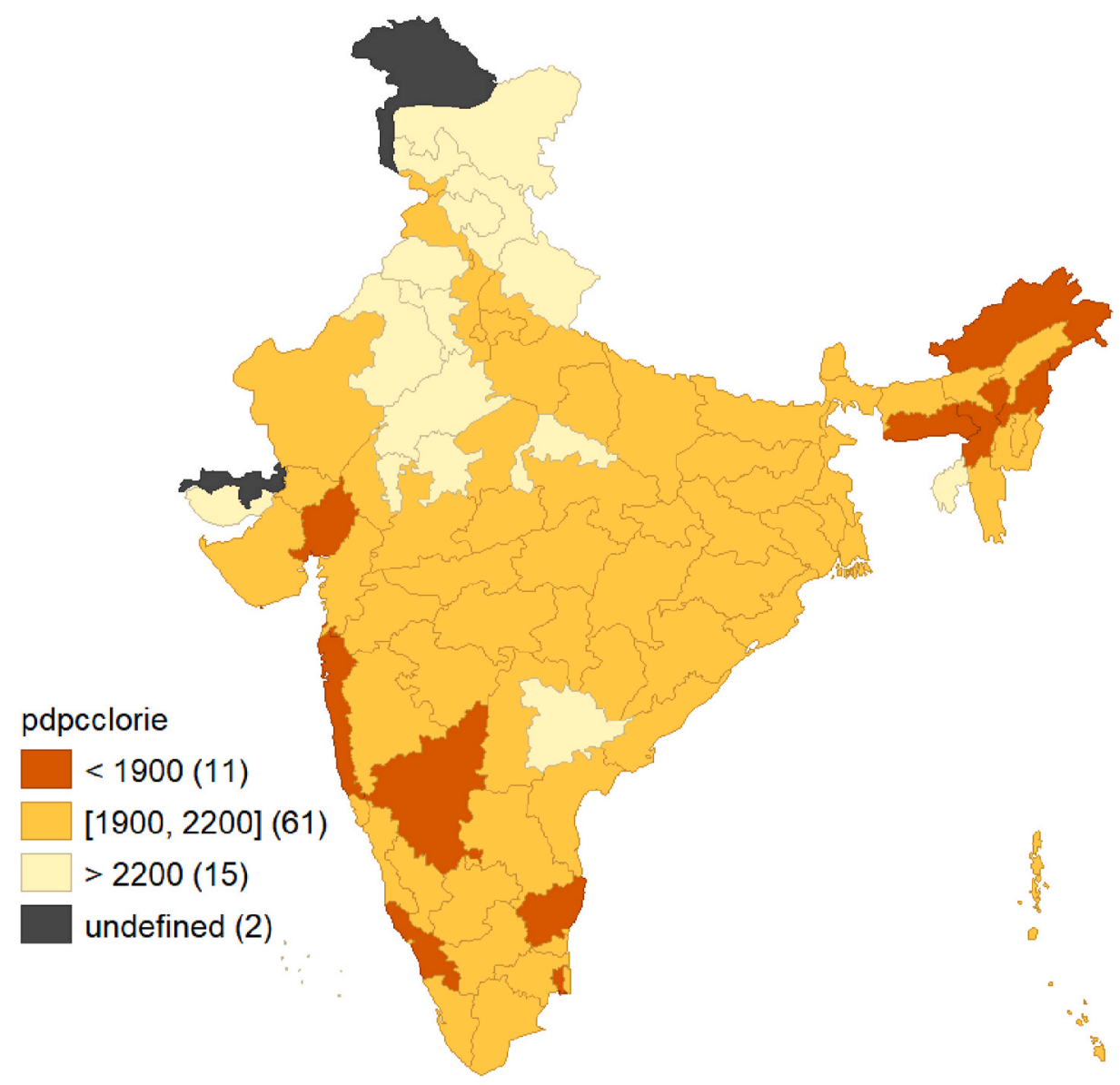

Fig. 1. Regional pattern of calories (per day per capita Kcal) intake across the regions of India, NSS, 2011-12. 


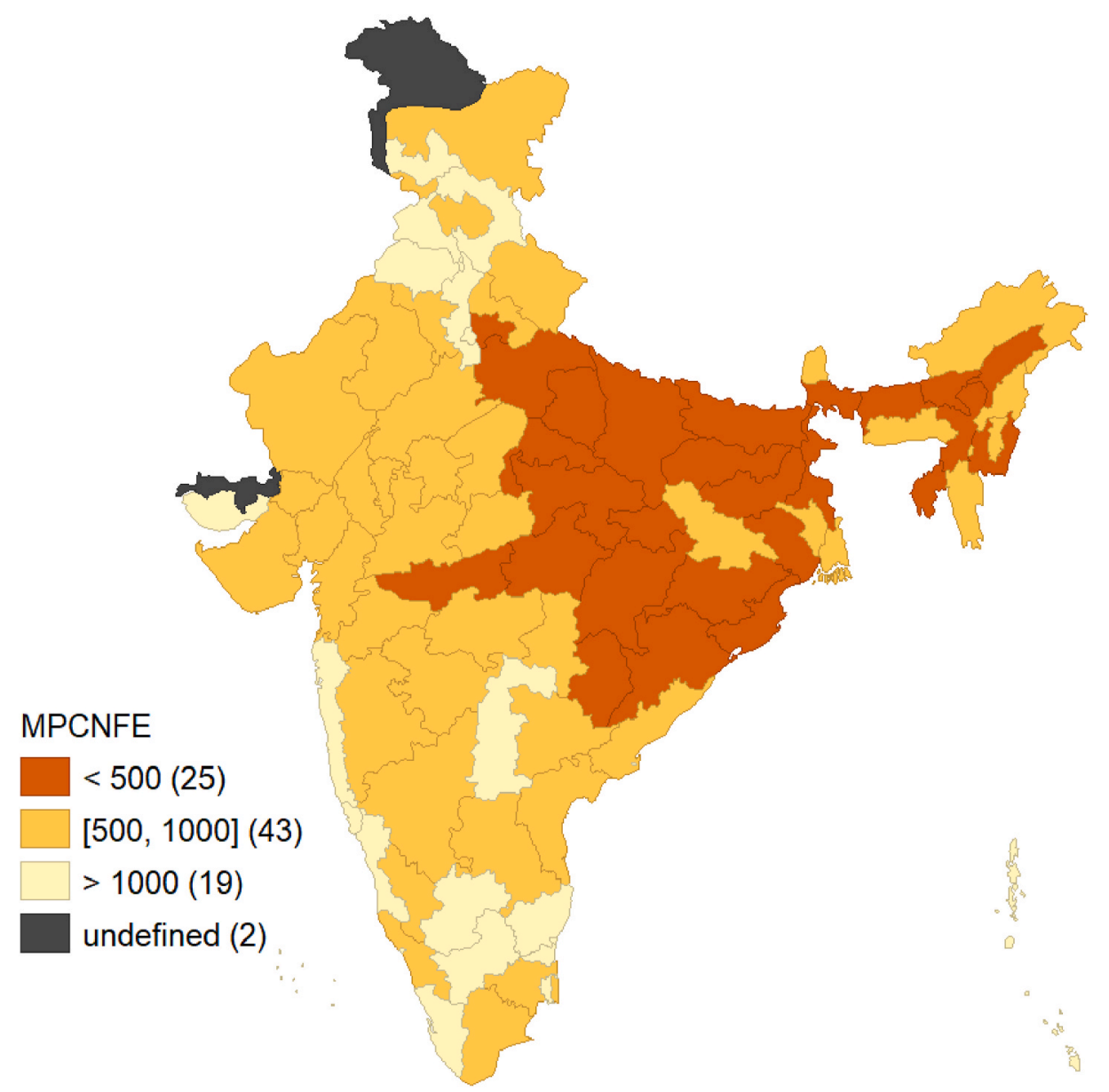

Fig. 2. Regional pattern of MPCNFE across India, NSS, 2011-12.

the clusters of regions where the MPCNFE is less than $500 \mathrm{Rs} /-$.

Fig. 3 provides the regional pattern of mean wealth score-an integrated PCA score of household-based asset indicators. Out of the 88 regions across India, 38 regions show lowest wealth score (less than $-0.2)$. These regions are mostly from Central, Eastern and North-Eastern part of India. Regions like Inland Central Maharashtra and Dadra \& Nagar Haveli from West, Inland Northern Karnataka from South India reflect lowest Wealth score of assets possession. On the other hand, 13 regions from Northern India show the highest wealth score in the range of 0.4-1.02. Rest of the regions, mostly from Western and Southern part of India show medium wealth score with moderate asset possession.

\subsection{Regional pattern of undernutrition in terms of stunting, underweight and wasting prevalence}

The regional prevalence of stunting, underweight and wasting are shown in Fig. 4, Fig. 5 and in Fig. 6 respectively. It is observed that there are around 29 regions across India where the prevalence of stunting is higher than national average and ranges in between $38 \%$ and $48 \%$. This shows that in these regions of India, more than two-fifth of the underfive children are stunted. These regions are clustered in the Central part of India with a spread towards few regions from Western and Southern India. Sothern Odisha from East and Meghalaya from NorthEast also fall under this category where the stunting prevalence is more than the national average. There are only 7 regions where the stunting prevalence is less than $25 \%$ and rest of the regions show moderately higher prevalence between $25 \%$ and $38 \%$. In case of underweight, it is again found that there are 32 regions where the prevalence is more than the national average. These regions are almost the same regions where the stunting prevalence is observed more than the national average. Regions like Outer Hills, Mountainous Jammu, Central Himachal Pradesh, Southern Punjab, Northern Punjab, Chandigarh from North India, Inland Tamil Nadu, Southern Kerala, Northern Kerala, Pondicherry from South India and few regions from West and North-East show the lowest underweight prevalence in India. On the other hand, a maximum of 36 regions across India show wasting prevalence more than the national average. Regions from the states of Rajasthan (Western Rajasthan, Southern Rajasthan, South-Eastern Rajasthan), Maharashtra (Coastal Maharashtra, Inland Western Maharashtra, Inland Central Maharashtra, Inland Northern Maharashtra, Eastern Maharashtra) and Gujarat (South-Eastern Gujarat, Plain Northern Gujarat, Dry Areas Gujarat and Saurashtra) form the clusters with high wasting prevalence in the Western part of India.

\subsection{Prevalence of undernutrition by region-level characteristics}

Table 1 provides the estimates of average prevalence of undernutrition across the 88 NSS regions of India by calorie consumption, monthly non-food expenditure, and wealth score and other regional characteristics. It is observed that with increasing calorie consumption (per day per capita), the reduction in undernutrition is not consistent and regions with 1900-2200 Kcal consumption show the highest prevalence in terms of stunting (35\%) and underweight (33\%). In terms of Monthly non-food expenditure, the trend shows a consistent decreasing pattern of undernutrition burden with increasing expenditure. And the highest burden of stunting, underweight and wasting prevalence is observed in those regions where the MPCNFE is less than 1000 Rs/-. The regional distribution of wealth score and prevalence of undernutrition 


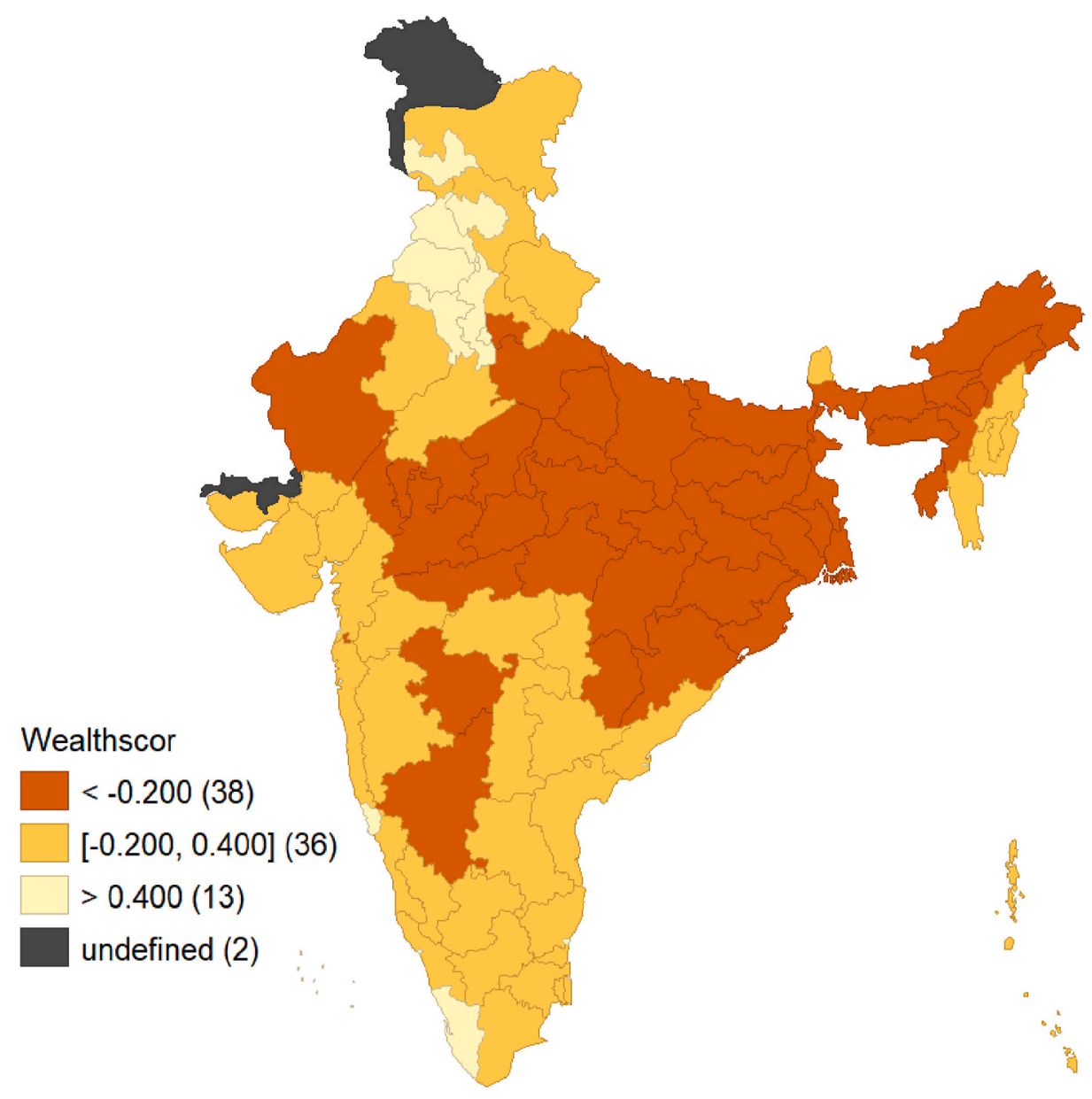

Fig. 3. Regional pattern of wealth score across India, NSS, 2011-12.

burden (except stunting) also shows an opposite relation and with increasing mean wealth score across the regions it shows decreasing prevalence of undernutrition across India. Regions with lowest mean wealth score $(<-0.2)$ are carrying the highest burden of child undernutrition in terms of underweight and wasting prevalence.

\subsection{Measures of correlation and scatteredness}

Table 2 provides a correlation matrix showing the linear association (correlation) between the measures of child undernutrition and calorie consumption, monthly non-food expenditure and wealth score across regions of India. The correlation matrix shows that regions with high burden of stunting also carry a significantly correlated higher burden of underweight and wasting prevalence. Noticeably, the bivariate correlation measures demonstrate that the regional pattern of calorie consumption does not show any statistically significant correlation with any of the measures of undernutrition. On the other hand, monthly per capita non-food expenditure (MPCNFE) is negatively correlated with the regional burden of stunting and underweight but not with wasting prevalence which tells that with increasing MPCNFE, the burden of stunting and underweight show a reduction across the regions. Apparently, wealth score shows high and statistically significant negative correlation with each of the measures of undernutrition. This shows that regions with higher wealth score carry lower burden of undernutrition prevalence in terms of stunting, underweight and wasting. The correlation matrix also shows a strong and positive correlation between MPCNFE and wealth score which informs that regions with higher MPCNFE also possess higher wealth. The two-way scatter plots confirm a negative slope between undernutrition MPCNFE and wealth score (see
Fig. 7a, 7b, 7c, 8a, 8b, 8c, 9a, 9b and 9c).

\subsection{Regression analysis}

Tables 3a, 3b and 3c show the regression estimates demonstrating the empirical association between measures of child undernutrition and calorie consumption, MPCNFE and wealth score estimates across regions of India. Tables $3 a-3 c$ give the unadjusted and adjusted association of undernutrition measures with calorie, MPCNFE and wealth score. The bivariate as well as the multivariate analysis show a statistically significant association of calorie, MPCNFE and wealth with Stunting. Once adjusted for other covariates, the model estimations show higher Rsquare value. Within the multivariate framework, calorie consumption is found significant predictor for all the three measures of undernutrition. The associated negative beta coefficients (adjusted) for calorie (log of calorie intake per day per capita) for all the three measures of child undernutrition suggests that with higher calorie consumption the burden of child undernutrition show a decreasing pattern across the regions of India. The calorie framework explains $45 \%$ of the regional variation in stunting, $52 \%$ in the prevalence of underweight and $38 \%$ in wasting. The MPCNFE shows statistically significant association with stunting and underweight as well but not for wasting. The adjusted coefficients for stunting as well as for underweight show a negative association suggesting higher MPCNFE expenditure is eventually associated with lower prevalence of stunting and underweight burden across the regions of India. Within a multivariate setting it is also observed that the MPCNFE framework explains the maximum variance in each of the measures of child undernutrition across the NSS regions of India. While, wealth as a measure of economic wellbeing of the household failed to 


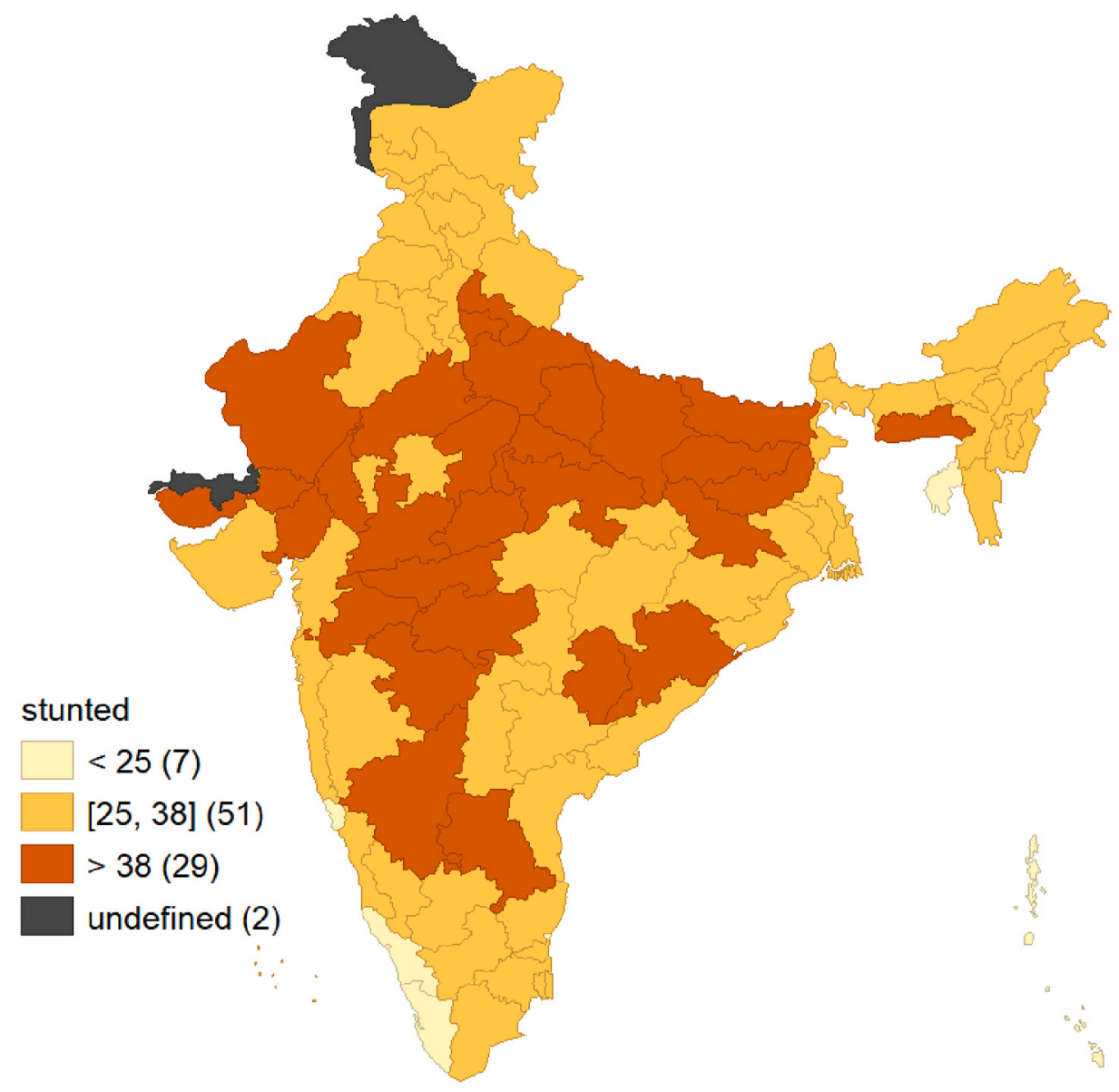

Fig. 4. Stunting prevalence across regions of India, NFHS, 2015-16.

show statistically significant association with each of the measures of undernutrition except for stunting within the multivariate setting. To mention, the wealth framework explains the lowest variation for each of the undernutrition measures among under-five children compared the other frameworks.

\section{Discussion}

This study demonstrates compelling evidence on the regional pattern of undernutrition, calories intake, monthly non-food expenditure and wealth across NSS regions of India using National Sample Survey (NSS) 68th round, 2011-12 and the National Family Health Survey (NFHS), 2015-16. Both the surveys are unique in terms of their prospects and the estimates it provides and complemented each other to conduct this study as if when NSS, 2011-12 lacked the specific information on child anthropometry, we compiled the specific information on anthropometric z-scores from NFHS, 2015-16 to calculate the regional estimates of stunting, underweight and wasting. Although there is a time gap in between the two surveys, still these two are the most recent rounds of surveys which provide the latest estimates of calories consumption, nonfood expenditure, wealth poverty and the estimates on undernutrition. Hence this study conducted the region level analysis to explore the phenomenon of child undernutrition in terms of calories intake, MPCNFE and wealth score.

This study is the first ever study to examine the region level phenomenon of child undernutrition subject to household level per day per capita calories intake, monthly non-food expenditure and wealth poverty measure holistically. The study quite comprehensively brings forth the regional estimates of the undernutrition parameters under study and provides a clear idea on the regional context of child undernutrition. From the study, it is evident that a large number of regions across India where average calorie consumption is less than 2200 Kcal per day per capita- the cut-off of ' $2200 \mathrm{Kcal}$ per day per capita' is considered independent of the rural-urban norm of calories intake as a large proportion of the population across the NSS regions constitute of the rural population. It is quite alarming to note that there are only 5 regions across India where the average household level calorie consumption is at least $2400 \mathrm{Kcal}$ per day per capita. In this study, we exclusively estimate the monthly non-food expenditure. The motivation of calculating MPCNFE is to create a measure of economic wellbeing of the household parallel to wealth measure of economic wellbeing disjoint to household's food expenditure because we have already included calories intake as a key exposure variable to predict undernutrition prevalence in this study.

The geographical distribution of the expenditure across India shows that almost all the regions (68 regions) in India only spend $1000 \mathrm{Rs} /-$ per month on an average whereas we find only 4 regions from Southern India where the MPCNFE expenditure is at least 1500 Indian rupees. Given the consumer durables, we estimated a robust measure on wealth and identified household's economic condition subject to household's possession of assets. And in terms of wealth condition, we find substantial poverty across the Eastern and North-Eastern regions of India. In these regions of India, on an average more than $50 \%$ of the population belongs to the wealth poor class. The geographical distribution of wealth (assets) demonstrates that wealth poverty is also concurrent with MPCNFE poverty and the wealth poor regions are those regions where monthly non-food expenditure is also low. So, this suggests that these regions are absolutely economically deprived and exposed to wealth as well as MPCNFE poverty simultaneously.

The regional estimates of undernutrition from NFHS, 2015-16 


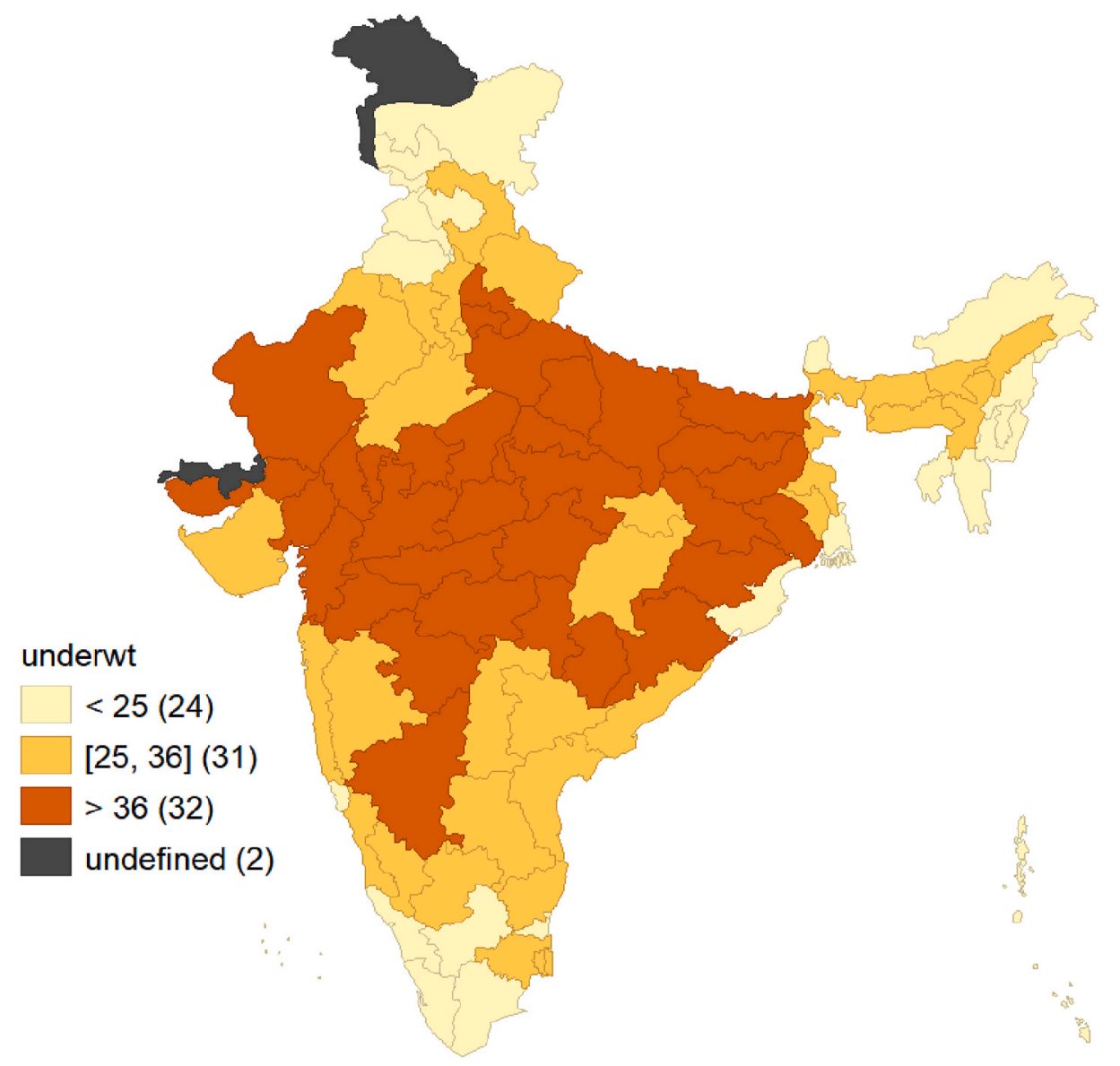

Fig. 5. Underweight prevalence across regions of India, NFHS, 2015-16.

suggests that regions from the central part of India are extremely burdened with higher prevalence of stunting, underweight and wasting. It is found that compared to 29 regions across India where the stunting prevalence is more than national average of $38 \%$ and there are total 32 regions where the underweight prevalence is more than the national average of $36 \%$. The regional distribution of stunting and underweight also shows that regions with higher burden of child undernutrition are all clustered across all the central and North-Western part of India. Though wasting prevalence is low across India than the other two measures of undernutrition; still, there are 36 regions where more than one-fifth of the children are wasted.

The correlation checks of undernutrition indicators and the concerned exposure variables of the study show the simple linear association between the variables with a preliminary understanding of the relationship. The measures of undernutrition show a statistically significant positive correlation with each other which hints that those regions which are burdened with one form of undernutrition are also burdened with the other forms of undernutrition. In this regard, the highest correlation is found between stunting and underweight $(\rho=$ 0.84 ; $\mathrm{p}$-value $<0.01$ ) followed by underweight and wasting ( $\rho=0.82$; $\mathrm{p}$ value $<0.01$ ). This high correlation indicates strong concurrent occurrence of stunting and underweight and underweight and wasting across the regions of India. On the other hand, cross-checking the correlation structure between the three exclusive exposure variables we find week linear association between calories intake and monthly non-food expenditure while wealth score across regions and MPCNFE across regions show positive correlation with high statistical significance. This indicates that regions with high MPCNFE show higher wealth score. The bivariate scatterplots also clearly depict the regional pattern between the three measures of undernutrition and the three concerned variables.
We also predict the regional pattern of stunting, underweight and wasting subject to the key exposure variables developed in this study within a bivariate regression setting as well as under a multivariate regression setting using OLS estimation. Through the bivariate OLS estimation, we check the independent predicting capacity of each of the key variables while the multivariate analysis checked the same once adjusted for the other socio-demographic confounding characteristics of the regions in India. The bivariate analysis confirms that the calorie association is consistently week for all the three measures of child undernutrition and explains a very negligible portion of the regional variation in stunting, underweight and wasting prevalence. But once adjusted for other confounders, we find improved estimates of calories intake (natural logarithm of calories intake) and the model also explains significantly higher variations. This suggests that the predicting capacity of calories intake is substantially influenced by the other confounding characteristics of the regions. On the contrary, the MPCNFE framework shows that MPCNFE itself can substantially predict the regional pattern of stunting and underweight and can independently explain a significant portion of the regional variation of these two measures of child undernutrition. Within a bivariate setting, wealth is not observed to be a statistically significant predictor of any of the measures of child undernutrition except in case of stunting within the multivariate framework. Thus, MPCNFE emerged as a consistent and strongest predictor of child undernutrition (stunting and underweight) across regions of India compared the other exposure variables.

This study involved two different sources of data to compile the relevant information to do a regional level analysis because not any single sources of data could stand alone to pertain the relevant information to explore the research questions developed in this study. Mainly, survey-specific data limitations remained the major motivation 


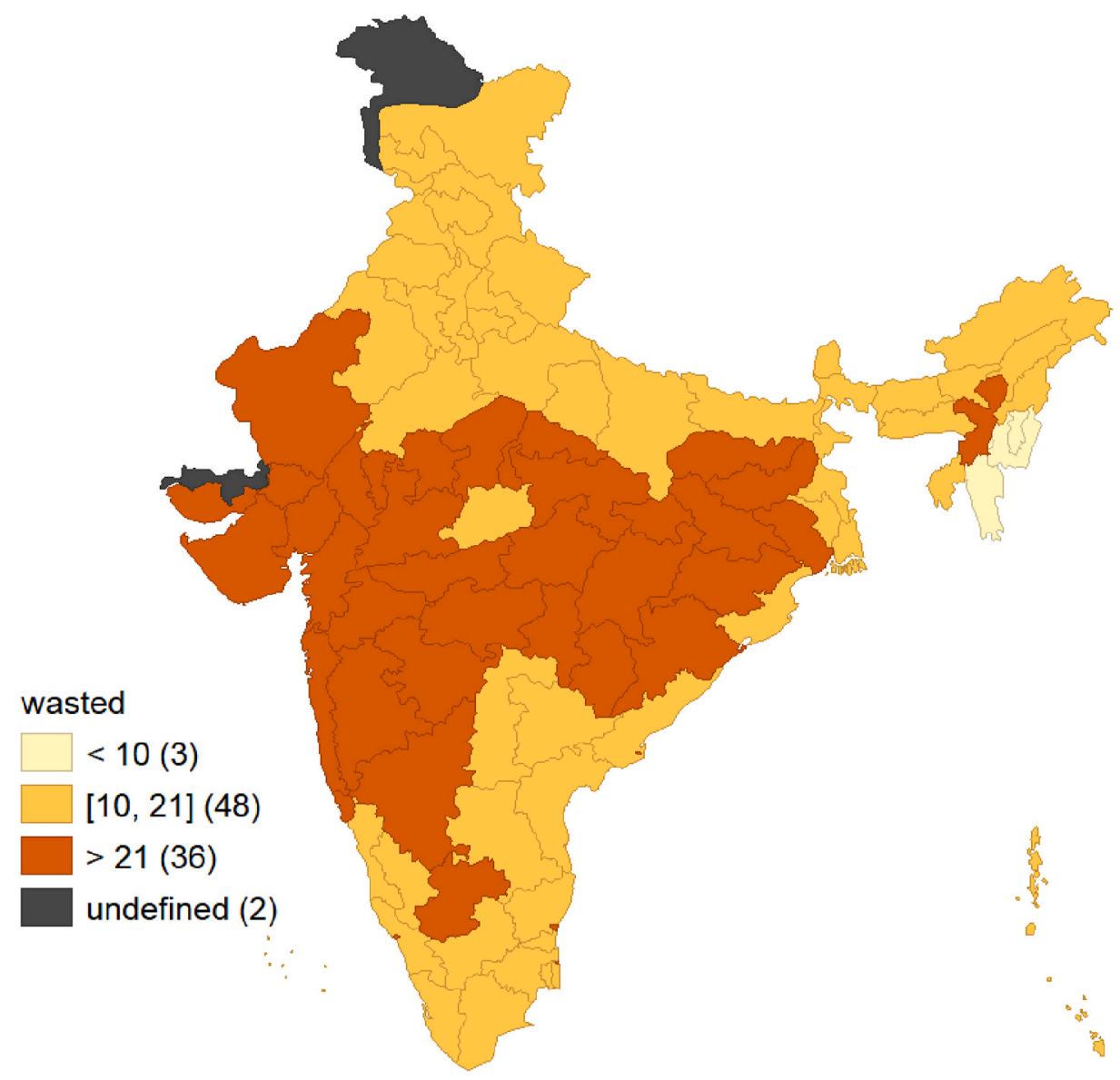

Fig. 6. Wasting prevalence across regions of India, NFHS, 2015-16.

of compiling the relevant data from multiple sources. Here, we would like to reiterate the fact that though these are different sources of data with different sampling strategies, yet, both the surveys-NSS and NFHS aim to provide population representative national and sub-national estimates. In this regard, NSS as a survey provides regional level lower disaggregated estimates beyond states; whereas, NFHS provides district level estimates beyond states. To mention, these NFHS districts are lower disaggregated administrative units than the NSS defined regions across India. Taking the advantage of NSS definition of regions, which actually constitutes of districts, we used the NFHS data information to derive the regional level prevalence of child undernutrition and other related demographic information. At the same time, NFHS collects the last five-year birth history prior to survey which actually reciprocates to those births that took place during the year of 2010-11 followed by the recent births. Considering the reference period of NFHS and the NSS survey and in the absence of pertinent data, this study could only execute an aggregated regional level analysis and is limited to a unit level analysis for any deeper insights. This study is also limited to the assumption that calories intake, non-food expenditure and wealth distribution across regions of India were not exposed to drastic change during the period of 2011-2016.

\section{Conclusion}

In India, child's nutritional status is assessed and monitored over time through different population-based surveys namely, National Family Health Survey (NFHS), District Level Household Survey (DLHS) and India Human Development Survey (IHDS). These surveys within panel/cross-sectional framework provide the estimates on undernutrition like, stunting, underweight, wasting and anaemia at the national, sub-national level and by population characteristics of the children. And thereby plays a crucial role to help the Government to monitor child's nutritional health and inform the population policies. While, different consumption expenditure rounds of National Sample Survey (NSS) provide the estimates on household level per capita calories consumption and per capita food and non-food expenditure across households. Given the research gap, this study exclusively examined the hypothesis "How does wealth, MPCNFE and calories intake are associated with stunting, underweight and wasting prevalence across regions of India". Here in this study, we find that as an independent predictor, calories intake is a weak predictor of undernutrition at the regional level compared to MPCNFE. As a measure of economic wellbeing of the household, MPCNFE emerged to be the strongest predictor of all the key exposure variables in this study. While, the relationship between wealth and measures of undernutrition have been found weak. The main limitation of this study is the integration of data information from two different sources of two different time points to compile the necessary information at the regional level; yet, this study essentially enlightens up the regional context of undernutrition burden among under-five children. At the same time, this study also recommends integration of different components in the household surveys. For example, NSS as a survey can actually collect the necessary information on child anthropometry and other demographic information of the child and NFHS being a core demographic health survey can also collect the crucial information on consumption expenditure and calories intake and serve as a holistic household survey on many fronts.

\section{Authors' contributions}

JK \& SKM conceptualized the study, designed the experiment. JK 
Table 1

Prevalence of stunting, underweight and wasting (\%) by region level characteristics, India, 2011-12.

\begin{tabular}{|c|c|c|c|c|c|c|}
\hline \multirow[t]{2}{*}{ Region level characteristics } & \multicolumn{2}{|c|}{ Stunting } & \multicolumn{2}{|c|}{ Underweight } & \multicolumn{2}{|c|}{ Wasting } \\
\hline & Mean & $\mathrm{CV}$ & Mean & $\mathrm{CV}$ & Mean & $\mathrm{CV}$ \\
\hline \multicolumn{7}{|l|}{ Calorie $^{a}$} \\
\hline$<1900$ & 33.82 & 0.24 & 29.45 & 0.32 & 21.27 & 0.28 \\
\hline $1900-2200$ & 34.90 & 0.23 & 32.72 & 0.31 & 20.62 & 0.30 \\
\hline $2200-2480$ & 30.94 & 0.20 & 26.88 & 0.34 & 18.50 & 0.38 \\
\hline \multicolumn{7}{|l|}{ MPCNFE $^{\mathrm{b}}$} \\
\hline$<1000$ & 39.32 & 0.17 & 32.99 & 0.31 & 20.65 & 0.32 \\
\hline $1000-1500$ & 31.43 & 0.18 & 25.87 & 0.22 & 19.53 & 0.27 \\
\hline $1500-2057$ & 26.08 & 0.19 & 21.50 & 0.22 & 17.50 & 0.36 \\
\hline \multicolumn{7}{|l|}{ Wealth score ${ }^{c}$} \\
\hline$<-0.2$ & 28.58 & 0.19 & 37.82 & 0.22 & 22.76 & 0.24 \\
\hline$-0.2-0.4$ & 37.10 & 0.16 & 27.41 & 0.33 & 18.92 & 0.36 \\
\hline $0.4-1.02$ & 40.89 & 0.16 & 23.00 & 0.20 & 17.15 & 0.28 \\
\hline \multicolumn{7}{|l|}{ Proportion rural } \\
\hline$<40$ & 29.00 & 0.12 & 27.00 & 0.21 & 18.75 & 0.40 \\
\hline $40-70$ & 32.19 & 0.23 & 29.10 & 0.32 & 20.39 & 0.32 \\
\hline $70-98$ & 35.51 & 0.22 & 32.83 & 0.32 & 20.40 & 0.30 \\
\hline \multicolumn{7}{|l|}{ Proportion no educated } \\
\hline$<20$ & 28.57 & 0.23 & 25.33 & 0.31 & 18.19 & 0.36 \\
\hline $20-40$ & 34.47 & 0.19 & 31.32 & 0.32 & 20.58 & 0.30 \\
\hline $41-56$ & 40.64 & 0.20 & 39.86 & 0.19 & 22.50 & 0.27 \\
\hline \multicolumn{7}{|l|}{ Proportion BPL ${ }^{\mathrm{d}}$} \\
\hline$<40$ & 33.04 & 0.24 & 30.00 & 0.32 & 20.19 & 0.31 \\
\hline $40-70$ & 36.84 & 0.21 & 33.04 & 0.35 & 20.44 & 0.34 \\
\hline $71-93$ & 32.33 & 0.19 & 33.78 & 0.22 & 20.78 & 0.25 \\
\hline \multicolumn{7}{|l|}{ Proportion of $S C \& S T^{e}$} \\
\hline $4-40$ & 33.43 & 0.24 & 30.71 & 0.29 & 20.00 & 0.27 \\
\hline $40-70$ & 36.65 & 0.18 & 36.29 & 0.30 & 24.12 & 0.24 \\
\hline $71-95$ & 33.38 & 0.19 & 24.75 & 0.52 & 14.75 & 0.61 \\
\hline \multicolumn{7}{|l|}{ Proportion of Hindu } \\
\hline $1-40$ & 30.44 & 0.19 & 18.78 & 0.31 & 11.78 & 0.35 \\
\hline $40-70$ & 30.00 & 0.27 & 24.83 & 0.32 & 17.25 & 0.16 \\
\hline $71-99$ & 35.25 & 0.22 & 34.07 & 0.27 & 22.01 & 0.27 \\
\hline
\end{tabular}

a Per day per capita calories intake.

b Monthly per capita non-food expenditure.

c Integrated PCA score of asset-based indicators.

d Below Poverty Line.

e Scheduled Caste \& Scheduled Tribe.

compiled the data, performed the analysis and prepared the primary draft of the manuscript. SKM edited and critically revised the manuscript. The manuscript is part of JK's Ph.D dissertation work. All authors read and approved the manuscript.

\section{Funding}

The study did not receive any funding or grant to conduct this study.

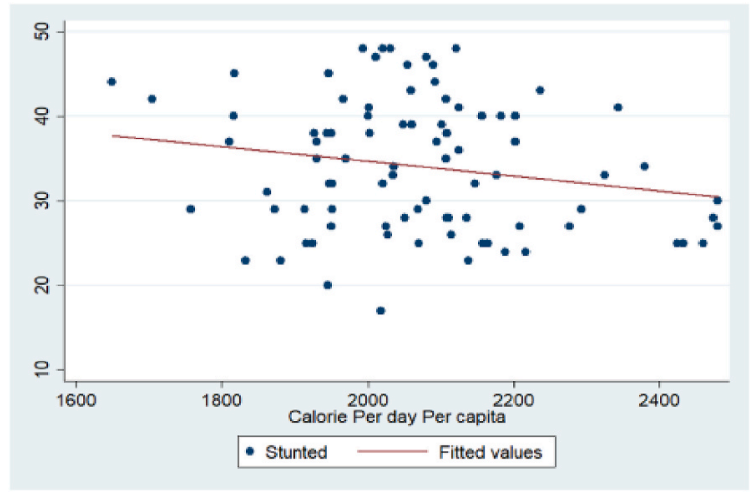

Fig. 7 a. Calorie vs Stunting in regions of India.

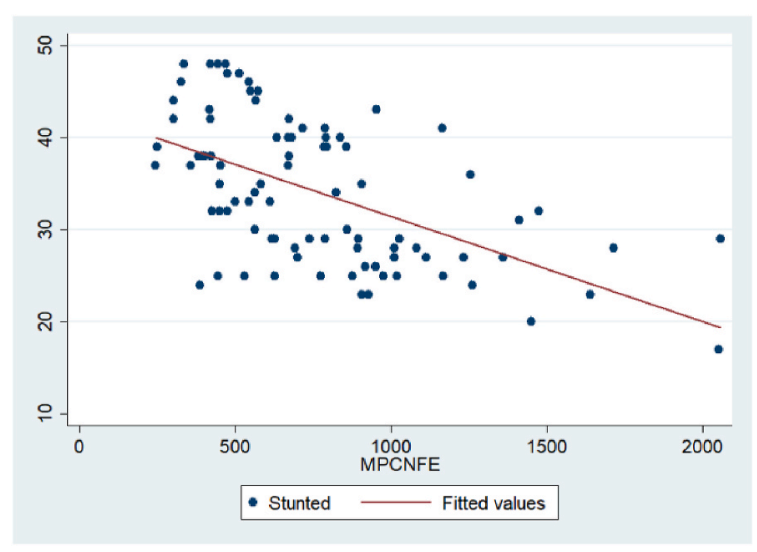

Fig. 7 (b). MPCNFE vs Stunting. in regions of India.

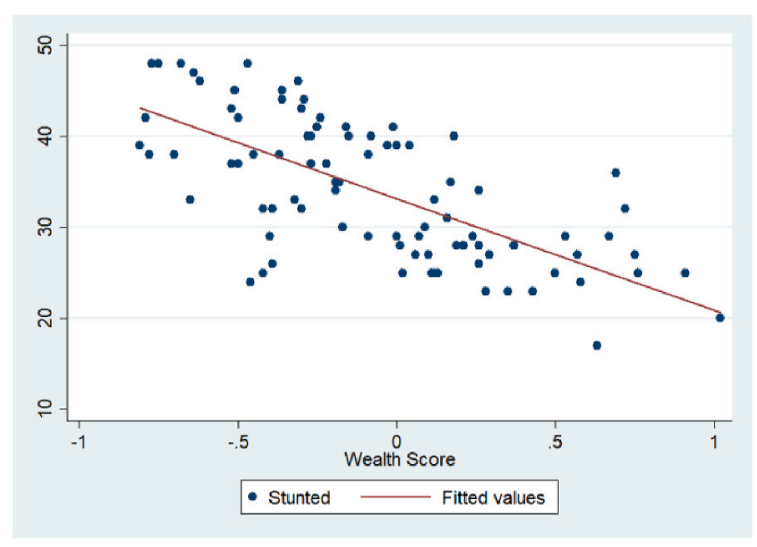

Fig. 7 (c). Wealth vs Stunting in regions of India.

Table 2

Correlation coefficient of Stunting, underweight \& wasting, calorie consumption and MPCNFE and wealth score in regions of India, 2011-12.

\begin{tabular}{llllll}
\hline Variables & Stunting & Underweight & Wasting & Calorie & MPCNFE \\
\hline Stunting & 1 & & & & \\
Underweight & $0.8364^{*}$ & 1 & 1 & & \\
Wasting & $0.5093^{*}$ & $0.8207^{*}$ & -0.1350 & 1 & 1 \\
Per capita calorie & -0.1922 & -0.1361 & -0.1614 & 0.0799 & 1 \\
MPCNFE & $-0.5568^{*}$ & $-0.4195^{*}$ & $-0.3323^{*}$ & 0.2361 & $0.7634^{*}$ \\
Wealth score & $-0.6873^{*}$ & $-0.6043^{*}$ & 1 & $1^{*}$ \\
\hline
\end{tabular}

Significance at level $1 \%$. 


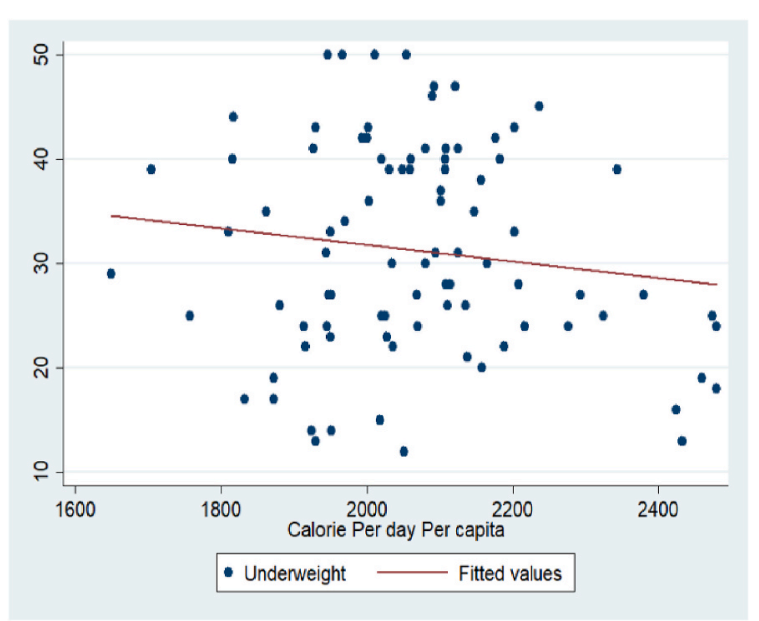

Fig. 8(a). Calorie vs Underweight in regions of India.

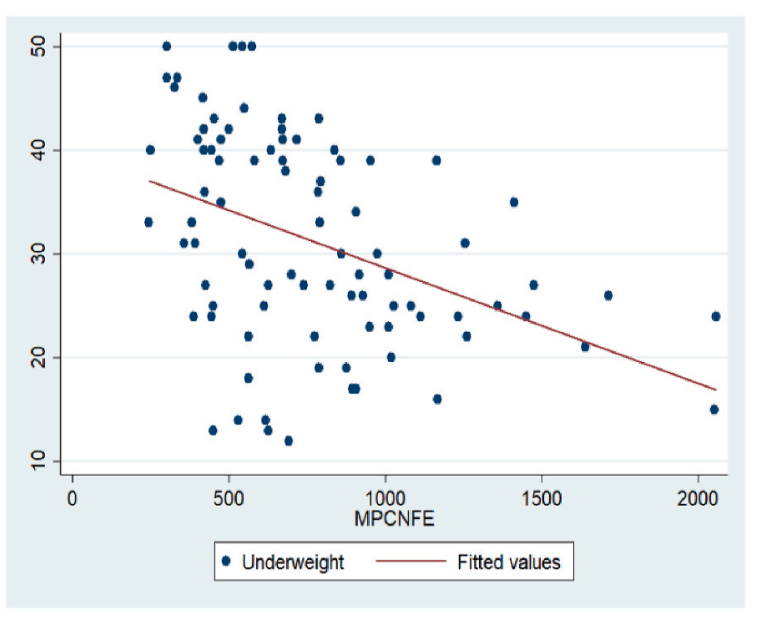

Fig. 8(b). MPCNFE vs Underweight in regions of India.

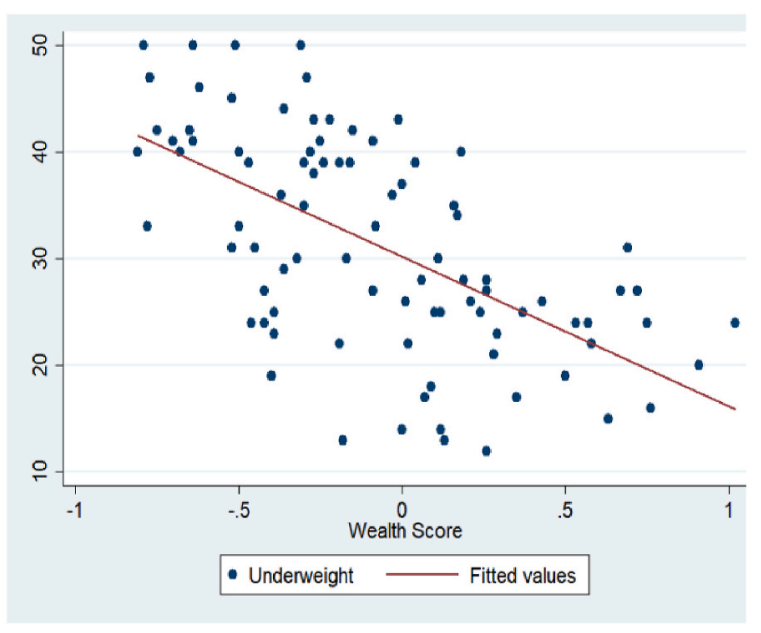

Fig. 8(c). Wealth vs Underweight in regions of India.

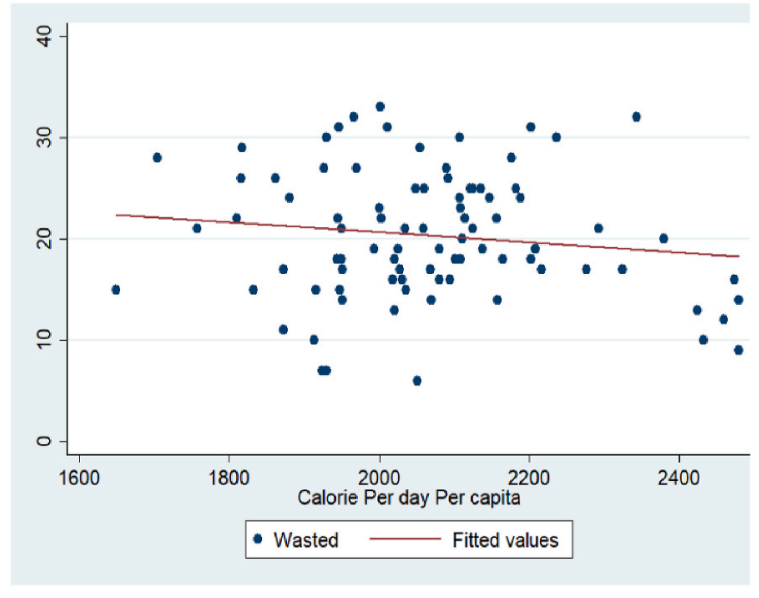

Fig. 9(a). Calorie vs Wasting in regions of India.

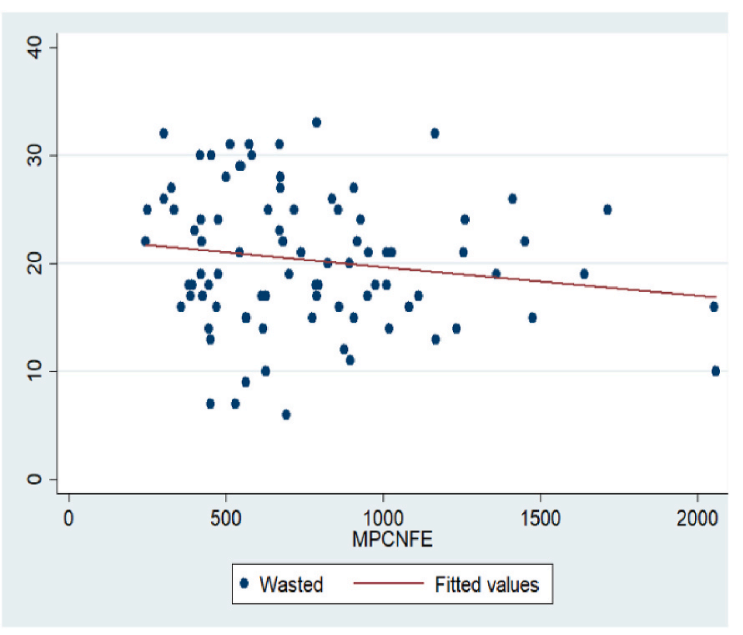

Fig. 9(b). MPCNFE vs Wasting in regions of India.

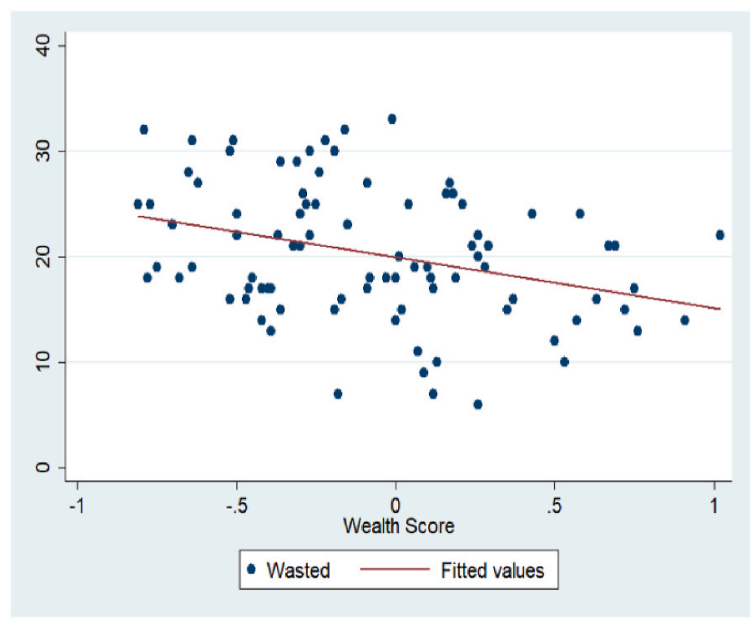

Fig. 9(c). Wealth vs Wasting in regions of India. 
Table3a

OLS estimation showing the association between stunting and calories intake, MPCNFE and wealth score, 2011-12.

\begin{tabular}{|c|c|c|c|c|c|c|c|c|c|c|c|c|}
\hline \multirow[t]{2}{*}{ Stunting } & \multicolumn{4}{|l|}{ Calorie } & \multicolumn{4}{|c|}{ MPCNFE } & \multicolumn{4}{|c|}{ Wealth score } \\
\hline & Coef. & p-value & $95 \% \mathrm{CI}$ & & Coef. & p-value & $95 \% \mathrm{CI}$ & & Coef. & p-value & $95 \% \mathrm{CI}$ & \\
\hline \multicolumn{13}{|l|}{ Unadjusted } \\
\hline \multirow[t]{2}{*}{ Log(calorie)/Log (MPCNFE)/Log(Wealth score) } & -17.48 & 0.08 & -37.33 & 2.37 & -9.33 & 0.00 & -12.23 & -6.42 & -1.11 & 0.14 & -2.59 & 0.37 \\
\hline & \multicolumn{4}{|c|}{ 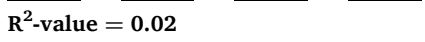 } & \multicolumn{4}{|c|}{$\mathrm{R}^{2}$-value $=0.31$} & \multicolumn{4}{|c|}{$\mathrm{R}^{2}$-value $=0.03$} \\
\hline Log(calorie)/Log (MPCNFE)/Log(Wealth score) & -34.16 & 0.00 & -50.11 & -18.21 & -9.73 & 0.00 & -13.64 & -5.82 & -1.59 & 0.05 & -3.14 & -0.04 \\
\hline Rural (\%) & 0.07 & 0.11 & -0.02 & 0.15 & -0.12 & 0.02 & -0.23 & -0.02 & -0.07 & 0.11 & -0.16 & 0.02 \\
\hline HH Head, No education (\%) & 0.37 & 0.00 & 0.25 & 0.49 & 0.28 & 0.00 & 0.16 & 0.39 & 0.13 & 0.16 & -0.05 & 0.31 \\
\hline BPL card $(\%)$ & -0.08 & 0.02 & -0.15 & -0.02 & -0.05 & 0.09 & -0.11 & 0.01 & -0.07 & 0.07 & -0.15 & 0.01 \\
\hline SC/ST (\%) & 0.11 & 0.00 & 0.03 & 0.18 & 0.06 & 0.11 & -0.01 & 0.13 & 0.09 & 0.04 & 0.01 & 0.18 \\
\hline Hindu (\%) & 0.07 & 0.02 & 0.01 & 0.13 & 0.04 & 0.16 & -0.02 & 0.10 & 0.06 & 0.07 & -0.01 & 0.13 \\
\hline $\mathrm{N}$ & \multicolumn{4}{|c|}{$\begin{array}{l}\text { Adj } R^{2} \text {-value }=0.45 \\
88\end{array}$} & \multicolumn{4}{|c|}{$\begin{array}{l}\text { Adj } R^{2} \text {-value }=0.48 \\
88\end{array}$} & \multicolumn{4}{|c|}{$\begin{array}{l}\text { Adj } R^{2} \text {-value }=0.16 \\
88\end{array}$} \\
\hline
\end{tabular}

Table3b

OLS estimation showing the association between underweight and calories intake, MPCNFE and wealth score, 2011-12.

\begin{tabular}{|c|c|c|c|c|c|c|c|c|c|c|c|c|}
\hline \multirow[t]{2}{*}{ Underweight } & \multicolumn{4}{|l|}{ Calorie } & \multicolumn{4}{|c|}{ MPCNFE } & \multicolumn{4}{|c|}{ Wealth score } \\
\hline & Coef. & p-value & $95 \%$ CI & & Coef. & p-value & $95 \% \mathrm{CI}$ & & Coef. & p-value & $95 \% \mathrm{CI}$ & \\
\hline \multicolumn{13}{|l|}{ Unadjusted } \\
\hline \multirow[t]{2}{*}{ Log(calorie)/Log (MPCNFE)/Log(Wealth score) } & -14.73 & 0.265 & -40.8 & 11.39 & -9.50 & 0.00 & -13.62 & -5.39 & -1.02 & 0.33 & -3.12 & 1.07 \\
\hline & \multicolumn{4}{|c|}{$\overline{\mathrm{R}^{2} \text {-value }}=\overline{0.0 .0029}$} & \multicolumn{4}{|c|}{$\overline{R^{2} \text {-value }=0.19}$} & \multicolumn{4}{|c|}{$\overline{R^{2} \text {-value }} \overline{=0.11}$} \\
\hline \multicolumn{13}{|l|}{ Multivariate } \\
\hline Log(calorie)/Log (MPCNFE)/Log(Wealth score) & -30.52 & 0.00 & -49.85 & -11.19 & -8.90 & 0.00 & -13.69 & -4.12 & -1.46 & 0.14 & -3.43 & 0.51 \\
\hline Rural (\%) & 0.03 & 0.52 & -0.07 & 0.14 & -0.14 & 0.03 & -0.27 & -0.01 & -0.10 & 0.07 & -0.21 & 0.01 \\
\hline HH Head, No education (\%) & 0.38 & 0.00 & 0.23 & 0.53 & 0.30 & 0.00 & 0.15 & 0.44 & 0.14 & 0.23 & -0.09 & 0.37 \\
\hline BPL card $(\%)$ & -0.07 & 0.09 & -0.15 & 0.01 & -0.04 & 0.25 & -0.12 & 0.03 & -0.05 & 0.33 & -0.15 & 0.05 \\
\hline SC/ST (\%) & 0.15 & 0.00 & 0.06 & 0.23 & 0.10 & 0.02 & 0.02 & 0.19 & 0.07 & 0.24 & -0.05 & 0.18 \\
\hline \multirow[t]{2}{*}{ Hindu (\%) } & 0.23 & 0.00 & 0.15 & 0.30 & 0.20 & 0.00 & 0.13 & 0.27 & 0.14 & 0.00 & 0.05 & 0.23 \\
\hline & \multicolumn{4}{|c|}{ Adj $R^{2}$-value $=0.52$} & \multicolumn{4}{|c|}{ Adj $R^{2}$-value $=0.54$} & \multicolumn{4}{|c|}{ Adj $R^{2}$-value $=0.29$} \\
\hline
\end{tabular}

Table3c

OLS estimation showing the association between wasting and calories intake, MPCNFE and wealth score, 2011-12.

\begin{tabular}{|c|c|c|c|c|c|c|c|c|c|c|c|c|}
\hline \multirow[t]{2}{*}{ Wasting } & \multicolumn{4}{|l|}{ Calorie } & \multicolumn{4}{|c|}{ MPCNFE } & \multicolumn{4}{|c|}{ Wealth score } \\
\hline & Coef. & p-value & $95 \% \mathrm{CI}$ & & Coef. & p-value & $95 \% \mathrm{CI}$ & & Coef. & p-value & $95 \% \mathrm{CI}$ & \\
\hline \multicolumn{13}{|l|}{ Bivariate } \\
\hline \multirow[t]{2}{*}{ Log(calorie)/Log (MPCNFE)/Log(Wealth score) } & -9.42 & 0.25 & -25.71 & 6.88 & -2.28 & 0.11 & -5.11 & 0.54 & -0.14 & 0.88 & -1.92 & 1.64 \\
\hline & \multicolumn{4}{|c|}{$\mathrm{R}^{2}$-value $=0.0037$} & \multicolumn{4}{|c|}{$\mathrm{R}^{2}$-value $=0.018$} & \multicolumn{4}{|c|}{$\overline{\mathrm{R}^{2} \text {-value }=\overline{0.0007}}$} \\
\hline Log(calorie)/Log (MPCNFE)/Log(Wealth score) & -14.53 & 0.04 & -28.32 & -0.74 & -1.55 & 0.39 & -5.11 & 2.02 & -0.43 & 0.61 & -2.14 & 1.28 \\
\hline Rural (\%) & 0.00 & 0.95 & -0.07 & 0.07 & -0.04 & 0.40 & -0.13 & 0.05 & -0.02 & 0.64 & -0.12 & 0.07 \\
\hline HH Head, No education (\%) & 0.10 & 0.06 & 0.00 & 0.21 & 0.07 & 0.17 & -0.03 & 0.18 & -0.01 & 0.92 & -0.21 & 0.19 \\
\hline BPL card $(\%)$ & -0.04 & 0.15 & -0.10 & 0.02 & -0.03 & 0.33 & -0.08 & 0.03 & -0.02 & 0.73 & -0.10 & 0.07 \\
\hline SC/ST (\%) & 0.07 & 0.02 & 0.01 & 0.14 & 0.07 & 0.04 & 0.00 & 0.13 & -0.03 & 0.60 & -0.12 & 0.07 \\
\hline \multirow[t]{2}{*}{ Hindu (\%) } & 0.16 & 0.00 & 0.11 & 0.21 & 0.16 & 0.00 & 0.11 & 0.21 & 0.09 & 0.02 & 0.02 & 0.17 \\
\hline & \multicolumn{4}{|c|}{$\overline{\text { Adj } R^{2} \text {-value }=0.38}$} & \multicolumn{4}{|c|}{ Adj $R^{2}$-value $=0.35$} & \multicolumn{4}{|c|}{ Adj $R^{2}$-value $=0.29$} \\
\hline
\end{tabular}

\section{Availability of data and materials}

The unit level data of NFHS, 2015-16 is publicly available from the Demographic Health Survey (DHS) data repository through www. dhsprogram.com/data/and could be accessed upon a data request subject to non-profit and academic interest only. Similarly, the unit level data of NSS, 2011-12 is publicly available through http://www.icssrda taservice.in/datarepository/index.php/catalog/107

\section{Ethics approval and consent to participate}

The data used in this study publicly available and thus no ethical approval is required further from any institutional review board.

\section{Consent for publication}

Not applicable

\section{Declaration of competing interest}

The authors declare no competing interests.

\section{Acknowledgements}

Not applicable 


\section{Appendix-1}

An exploratory framework to understand the regional variation in child nutrition in India.

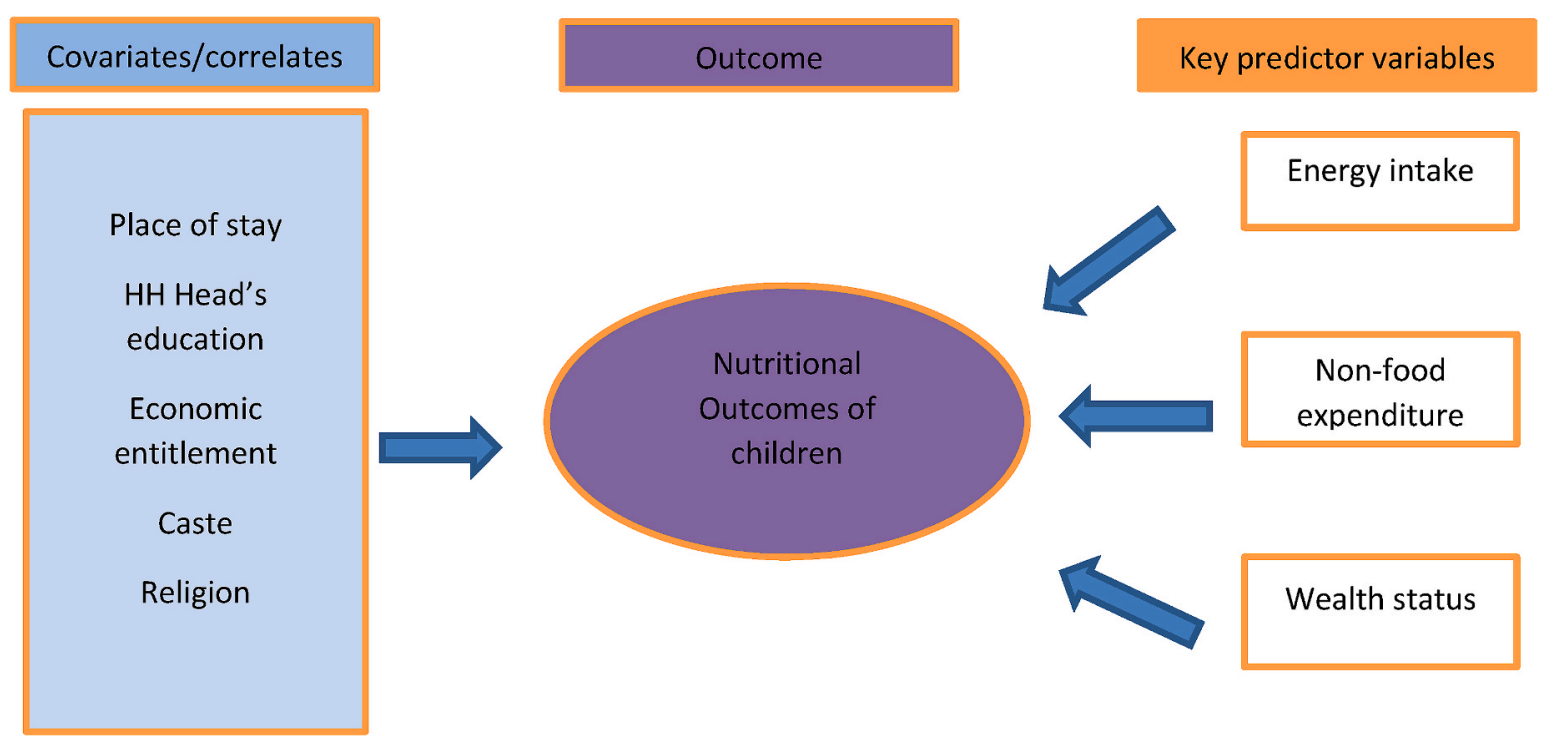

\section{References}

1 Sciences, I.I.f.P. \& ICF. National Family Health Survey (NFHS-4), 2015-16: India. IIPS Mumbai; 2017.

2 NSS G. Household Consumer Expenditure Among Socio-Economic Groups: 2004-2005 NSS 61 St Round (July 2004-June 2005). Report; 2007.

3 Office, N.S.S. Nutritional Intake in India, 2011-12. Ministry of Statistics and Programme Implementation, Government of India; 2014.

4 Sciences, I.I.f.P. \& MEASURE/DHS+, O.M.. India National Family Health Survey (NFHS-2), 1998-99. Mumbai, India: International Institute for Population Sciences; 2000.

5 Sciences IIfP. National Family Health Survey (NFHS-3), 2005-06: India. International Institute for Population Sciences; 2007.

6 Commission P. Press Note on Poverty Estimates. 2013:2011-2012.

7 Rutstein SO, Johnson K. The DHS Wealth Index. DHS Comparative Reports No. 6. Calverton: ORC Macro; 2004.

8 Meyer BD, Sullivan JX. Identifying the disadvantaged: official poverty, consumption poverty, and the new supplemental poverty measure. J Econ Perspect. 2012;26: $111-136$.

9 Tendulkar SD. Expert Group on Methodology for Estimation of Poverty. Planning Commission, Government of India; 2013.

10 Manual A. Dietary guidelines for Indians. Nat Inst Nutrition. 2011:2:89-117.

11 Khan J, Mohanty SK. Spatial heterogeneity and correlates of child malnutrition in districts of India. BMC Public Health. 2018;1027(2018). https://doi.org/10.1186/ s12889-018-5873-2 